\title{
Efeito do período de maturação de grãos nas propriedades físicas e reológicas de trigo
}

\author{
Effect of the maturation period of grains on the physical and rheological properties of wheat
}

\author{
Luiz Carlos GUTKOSKI ${ }^{1 *}$, Angelise DURIGON², Simone MAZZUTTI², \\ Amilton César Telo da SILVA², Moacir Cardoso ELIAS ${ }^{3}$
}

\begin{abstract}
Resumo
O trabalho objetivou estudar o efeito do período de maturação de grãos nas propriedades físicas e reológicas da farinha de trigo, avaliado através das determinações de peso do hectolitro, peso de mil grãos, grau de extração, proteínas, cinzas, umidade, cor, número de queda, alveografia, farinografia e amido danificado. Amostras dos genótipos BRS 179, Rubi, Fundacep 30 e Fundacep 51, safra 2006/2007 foram armazenadas em sacos de papel Kraft com $10 \mathrm{~kg}$ de trigo, em ambiente com temperatura de $22^{\circ} \mathrm{C}$ e umidade relativa do ar de $65-75 \%$. Cada tratamento foi composto por um genótipo e as avaliações realizadas nos tempos $0,15,30$, 60 e 90 dias de maturação. O experimento foi conduzido em delineamento inteiramente casualizado em arranjo fatorial $4 \times 5$. Os resultados foram analisados pelo emprego da análise de variância (Anova) e nos modelos significativos pelo teste $F$, e a comparação de médias pelo teste de Tukey a 5\% de probabilidade. Com o aumento do período de maturação do trigo a farinha apresentou melhores propriedades físicas e reológicas avaliadas pelas alterações de número de queda, cor, alveografia e farinografia. Os resultados de atividade enzimática, luminosidade, intensidade de amarelo e força geral do glúten se mostraram efetivos na avaliação de propriedades físicas e reológicas, enquanto as avaliações de amido danificado e estabilidade não foram indicadores adequados. O trigo não deve ser comercializado após a colheita, pois apresenta melhoria na classificação comercial, sendo indicado período de maturação de 60 dias. Os genótipos de trigo BRS 179 e Fundacep 51 passaram das classes brando para pão, enquanto o Rubi de pão para melhorador, indicando maior valor tecnológico e comercial com o aumento do período de maturação dos grãos de trigo.

Palavras-chave: Triticum aestivum; pós-colheita; alveografia; farinografia.
\end{abstract}

\begin{abstract}
The aim of this study was to investigate the effect of the maturation period of grains on the physical and rheological properties of wheat flour analyzed by determining the hectoliter weight, weight of thousand grains, experimental milling, proteins, ashes, moisture, color, falling number, alveography, farinography, and damaged starch. Samples of genotypes BRS 179, Rubi, Fundacep 30, Fundacep 51, and 2006/2007 crop, were stored in Kraft paper bags with $10 \mathrm{~kg}$ of wheat, at environment temperature of $22{ }^{\circ} \mathrm{C}$ and air humidity between $65-75 \%$. Each treatment consisted of one genotype and the measurements were made at zero, 15, 30, 60, and 90 days of maturation. The experiment was carried out in fully randomized factorial design at $4 \times 5$. The results were analyzed by variance analysis (Anova) and the means compared by Tukey's test at $5 \%$ probability. With the increase in the maturation period of wheat, the flour presented the best physical and rheological properties assessed by the changes of the falling number, color, alveography, and farinography. The results of the enzymatic activity, luminosity, yellow intensity, and general gluten strength were effective in the evaluation of physical and rheological properties while the assessments of damaged starch and stability were not appropriate indicators. The wheat should not be sold after harvest, since its commercial classification improvement indicates a maturation period of 60 days. The genotypes of wheat BRS 179 and Fundacep 51 genotypes changed from bland to bread and from Rubi bread to improved indicating higher technological and commercial value with the increase in the maturation period of the wheat grains.
\end{abstract}

Keywords: Triticum aestivum; post-harvest; alveography; farinography.

\section{Introdução}

O trigo é de grande importância para a economia brasileira, devido ao elevado consumo de seus derivados, principalmente pão, macarrão e biscoitos. No entanto, a produção nacional do grão não tem sido suficiente para atender à demanda, sendo agravada pela grande quantidade de grãos perdidos ou colhidos com qualidade inferior devido ao ataque de pragas, germinação na espiga e redução de matéria seca que ocorrem pelo retardo na colheita (CARNEIRO, 2005).
A secagem de trigo é uma operação crítica na seqüência do processo de pós-colheita e, quando não realizada adequadamente, pode provocar alterações significativas na qualidade do grão. O trigo colhido com umidade superior a 13\% de água deve ser submetido à secagem antes da operação de armazenamento. Em lotes com mais de $16 \%$ de umidade, a secagem deve ser lenta para evitar danos físicos no grão e realizada de forma que a temperatura máxima na massa de grãos não ultrapasse $43^{\circ} \mathrm{C}$, para manutenção

Recebido para publicação em 11/7/2007

Aceito para publicação em 19/4/2008 (002660)

${ }^{1}$ Faculdade de Agronomia e Medicina Veterinária, Universidade de Passo Fundo - UPF, CP 611, CEP 99001-970, Km 171, BR 285, São José, Passo Fundo - RS, Brasil,

E-mail: gutkoski@upf.br

2 Faculdade de Engenharia e Arquitetura - FEAR, Universidade de Passo Fundo - UPF, Passo Fundo - RS, Brasil

${ }^{3}$ Faculdade de Agronomia Eliseu Maciel, Universidade Federal de Pelotas - UFPel, CP 354, CEP 96010-900, Pelotas - RS, Brasil

${ }^{*}$ A quem a correspondência deve ser enviada 
da qualidade tecnológica do produto (ELIAS, 2002). Os principais aspectos que devem ser considerados no armazenamento de trigo, uma vez limpo e seco, são umidade e temperatura de armazenamento, ocorrência de pragas e fungos, que danificam os grãos e alteram a qualidade tecnológica da farinha, dificultando a comercialização (FLEURAT-LESSARD, 2002; KOCH; PRINGAS; MAERLAENDER, 2006).

Carneiro et al. (2005), estudando a influência da época de colheita, secagem artificial e período de armazenamento na qualidade de grãos de trigo comum e duro, verificaram redução significativa da atividade da enzima alfa-amilase com o retardo da colheita. A antecipação da colheita e da secagem não afetou a qualidade dos grãos e, com a armazenagem, ocorreu aumento da força geral de glúten e redução na atividade amilolítica da farinha do trigo. A melhor qualidade da farinha de trigo armazenado por oito meses pode estar relacionada às modificações bioquímicas, com alteração da qualidade tecnológica do grão.

É bem conhecido que, sob condições ideais de armazenamento, a farinha de trigo mantém sua funcionalidade por vários meses. Contudo, em altas temperaturas, como as que ocorrem freqüentemente em países tropicais durante o verão, a deterioração é acelerada. Cenkowski et al. (2000), estudando o efeito da temperatura de armazenamento nas propriedades reológicas da farinha de trigo compactada, verificaram, através de análises de alveografia, que a oxidação é afetada pela temperatura de armazenamento da farinha.

Conforme Hrusková e Machová (2003), as propriedades da farinha mudam durante o processo de maturação, com início de 3 a 4 dias após a moagem e término em aproximadamente 3 semanas. O tempo de maturação é importante para definir a ótima qualidade de panificação da farinha, embora esse período seja afetado por muitos fatores que dependem tanto das características da farinha quanto das condições ambientais de armazenamento. A umidade da farinha variou em função das condições ambientais de armazenamento. Os valores de acidez e de número de queda da farinha armazenada por três meses aumentaram significativamente. As características alveográficas indicaram melhoria nas propriedades de panificação da farinha em função do tempo e das condições de armazenamento.

Chen e Schofield (1996), avaliando as alterações do conteúdo de glutationa livre na qualidade de panificação de farinha de trigo armazenada em temperatura ambiente durante o período de 40 dias, verificaram que as formas reduzidas (GSH) e oxidadas (GSSG) diminuíram durante os 10 primeiros dias, permanecendo constante no restante do período estudado e, de forma concomitante, ocorreu aumento no volume dos pães. As alterações nos teores de glutationa e de qualidade de panificação ocorreram no mesmo espaço temporal, porém a natureza das reações que levaram a uma diminuição dos níveis presentes na farinha necessita ser mais bem elucidada.

A qualidade do grão de trigo pode ser definida como resultado da interação que a cultura sofre no campo, as condições do solo, clima, incidência de pragas e moléstias, manejo da cultura, cultivar, bem como das operações de colheita, secagem, armazenamento, moagem e das características genéticas (POMERANZ, 1987). Dada a grande diversidade de farinhas de trigo, é necessária a utilização de vários métodos para determinar essas características. Os métodos mais utilizados são os relacionados com as características reológicas da massa, a partir de sistemas simples de mistura de água e farinha. Existe uma série de aparelhos para medir estas propriedades, tais como farinógrafo, extensógrafo e alveógrafo. A definição de uso final de uma farinha deve ser feita após a avaliação conjunta destes resultados (2003). Os valores de peso do hectolitro, número de queda, força geral do glúten, tempo de mistura, estabilidade da massa, são usados para estabelecer o ágio ou deságio do trigo produzido e permitem que o mercado ofereça produtos com características perfeitamente identificáveis. Incluem-se nestes, trigos para usos como os diferentes tipos de pães, produção de biscoitos, produção de massas alimentícias e até mesmo para ração (BACALTCHUK, 1999).

O objetivo do trabalho foi estudar o efeito do período de maturação pós-colheita de grãos nas propriedades físicas e reológicas da farinha, avaliado através das determinações de peso do hectolitro, peso de mil grãos, grau de extração, proteínas, cinzas, umidade, número de queda, alveografia, farinografia e amido danificado nos genótipos de trigo BRS 179, Rubi, Fundacep 30, Fundacep 51.

\section{Material e métodos}

\subsection{Material}

Amostras de grãos de trigo (Triticum aestivum, L), genótipos BRS179, Rubi, Fundacep 30 e Fundacep 51, da safra agrícola 2006/2007 foram fornecidas pela Cooperativa Tritícola Mista Campo Novo (Cotricampo), Campo Novo, RS. A colheita dos grãos foi realizada com colhedora automotriz, a pré-limpeza em máquina de ar e peneiras e a secagem em secador contínuo. As análises foram realizadas no laboratório de Cereais do Centro de Pesquisa em Alimentação da Universidade de Passo Fundo.

Os grãos de trigo foram armazenados por um período de 90 dias em sacos de papel Kraft, com $10 \mathrm{~kg}$ de amostra, em ambiente com temperatura de $22{ }^{\circ} \mathrm{C}$ e umidade relativa do ar de $65-75 \%$. Cada tratamento foi composto por um genótipo e as avaliações realizadas periodicamente, nos tempos 0,15 dias, 30 dias, 60 dias e 90 dias. As avaliações do tempo zero de maturação foram realizadas logo após a secagem do trigo.

\subsection{Análises}

\section{Peso do hectolitro (PH)}

$\mathrm{O} \mathrm{PH}$ foi determinado no tempo zero de maturação do trigo em aparelho marca Dalle Molle (Balanças Dalle Molle Ltda, Caxias do Sul, Brasil), realizado de acordo com a metodologia descrita por Regras de Análise de Sementes (1992), em triplicata e os resultados foram expressos em kg.hL $\mathrm{hL}^{-1}$.

\section{Peso de mil grãos (PMG)}

O PMG foi determinado no tempo zero de maturação do trigo, de acordo com a metodologia descrita por Regras de Análise de Sementes ${ }^{3}$ pela contagem manual de 50 grãos em quadruplicata e os resultados foram expressos em gramas. 


\section{Análise por infravermelho proximal (NIR)}

Os teores de cinzas, proteína bruta e umidade foram determinados no tempo zero de maturação do trigo, pelo uso do NIR, marca Perstorp Analytical, modelo 5000. As curvas de calibração foram construídas pelo laboratório de Físico-Química do Centro de Pesquisa em Alimentação (Cepa), utilizando metodologia recomendada pela AACC (1995), e foram realizadas em triplicata. Os resultados médios das leituras foram expressos em porcentagem e em base seca. $\mathrm{O}$ valor de proteína bruta foi obtido pelo uso do fator 6,25 .

\section{Moagem experimental}

As amostras de grãos de trigo foram limpas no separador de impurezas modelo Sintel, marca Intecnial. A umidade foi determinada em aparelho de condutividade dielétrica, marca Gehaka, modelo G 600. As amostras foram condicionadas para a umidade de $16 \%$. A moagem foi realizada nos tempos 0,15 , 30, 60 e 90 dias de maturação de trigo em moinho piloto marca Chopin, de acordo com o método número 26-10 da AACC (1995), através de uma passagem pelo sistema de quebra e duas pelo sistema de redução, sendo determinadas as porcentagens de farinha de quebra e de extração.

\section{Número de queda}

$\mathrm{O}$ número de queda da farinha foi determinado nos tempos 0, 15, 30, 60 e 90 dias de maturação do trigo através do uso do aparelho Falling Number, modelo 1500 Fungal (Perten Instruments, Suíça) de acordo com o método 56-81B da AACC (1995), utilizando sete gramas de amostra, corrigido para $14 \%$ de umidade e realizado em duplicata e os resultados foram expressos em segundos.

\section{Cor}

A cor da farinha foi determinada nos tempos $0,15,30,60 \mathrm{e}$ 90 dias de maturação do trigo em espectrofotômetro de reflectância difusa marca Hunter Lab, modelo ColorQuest II, com sensor ótico geométrico de esfera. $\mathrm{O}$ aparelho foi calibrado com cerâmica, realizando-se a leitura por reflexão e ângulo de observação de $2^{\circ}$, iluminante principal D75 e iluminante secundário D65. No sistema Hunter de cor, corrigido pela CIE, os valores $\mathrm{L}^{*}$ (luminosidade) variam entre zero (preto) e 100 (branco), $-\mathrm{a}^{\star}$ (verde) até $+\mathrm{a}^{\star}$ (vermelho), $\mathrm{e}-\mathrm{b}^{\star}$ (azul) até $+\mathrm{b}^{\star}$ (amarelo). As amostras, apresentando opacidade comprovada e granulometria inferior a $250 \mu \mathrm{m}$ foram transferidas para cubetas de quartzo do próprio aparelho, compactadas, colocadas sobre o sensor ótico de 1", realizando-se duas repetições para cada amostra e a leitura em duas posições diferentes.

\section{Alveografia}

As características viscoelásticas da farinha de trigo foram determinadas nos tempos 0, 15, 30, 60 e 90 dias de maturação em alveógrafo Chopin, modelo NG (Villeneuve-la-Garenne Cedex, França) utilizando o método no 54-30 da AACC (1995), através da pesagem de 250 gramas de farinha e volume de $129,4 \mathrm{~mL}$ de água, corrigido na base de 14\% de umidade. Os parâmetros obtidos nos alveogramas são tenacidade $(\mathrm{P})$, que mede a sobrepressão máxima exercida na expansão da massa ( $\mathrm{mm})$; extensibilidade (L), que mede o comprimento da curva $(\mathrm{mm})$ e energia de deformação da massa $(\mathrm{W})$, que corresponde ao trabalho mecânico necessário para expandir a bolha até a ruptura, expressa em $10^{-4} \mathrm{~J}$.

\section{Farinografia}

As características de mistura da massa foram determinadas nos tempos 0, 15, 30, 60 e 90 dias de maturação do trigo, em aparelho promilógrafo marca Max Egger, modelo T6 (Blasen, Áustria), pelo uso de $100 \mathrm{~g}$ de farinha de trigo na umidade corrigida para $14 \%$ e realizadas de acordo com as recomendações do manual do aparelho (PROMYLOGRAPH, 2001). Os parâmetros avaliados foram absorção de água, que indica a qualidade da farinha refletida pela capacidade de intumescimento do glúten e o teor de amido danificado; tempo de desenvolvimento, que corresponde ao intervalo decorrente desde a primeira adição de água até o ponto de máxima consistência (pico); estabilidade, definida como a diferença de tempo entre o ponto em que o topo da curva intercepta a linha média de 500 UP e o ponto da curva que deixa a linha.

\section{Amido danificado}

O amido danificado da farinha de trigo foi determinado nos tempos 0, 15, 30, 60 e 90 dias de maturação, realizado de acordo com o procedimento no 76-30A da AACC (1995), através da hidratação das amostras de farinha de trigo, seguido de hidrólise enzimática por alfa-amilase fúngica de Aspergillus oryzae Sigma A6211 em maltose. Para a determinação dos açúcares redutores, foi utilizado o método $\mathrm{n}^{\circ}$ 60-80 da AACC (1995), e o teor de amido danificado foi expresso em gramas de amido hidrolisado por $100 \mathrm{~g}$ de amostra na base de $14 \%$ de umidade, em duplicata.

\section{Delineamento experimental e análise estatística}

O experimento foi conduzido em delineamento inteiramente casualizado em arranjo fatorial $4 \times 5$, ou seja, 4 genótipos de trigo (BRS 179, Rubi, Fundacep 30 e Fundacep 51) e 5 tempos de maturação $(0,15,30,60,90$ dias $)$. Os resultados foram analisados pelo emprego da análise de variância (Anova) e nos modelos significativos pelo teste $F$, realizada a comparação múltipla de médias pelo emprego do teste de Tukey a 5\% de probabilidade de erro. $\mathrm{O}$ processamento de dados e a análise estatística foram realizados com o uso do programa estatístico SAS ${ }^{\circledast}$ (1985). As análises e os gráficos das equações de regressão foram elaborados com o auxílio do programa estatístico Microsoft Excel $^{\oplus}$, no modo estatístico.

\section{Resultados e discussão}

\subsection{Caracterização da matéria-prima}

A Tabela 1 apresenta os valores de umidade do grão, peso do hectolitro e peso de mil grãos de amostras de trigo dos genótipos BRS 179, Rubi, Fundacep 30 e Fundacep 51. As amostras de trigo apresentaram umidade abaixo de 13\%, estando em acordo com o exigido pela Instrução Normativa SARC $\mathrm{n}^{\circ} 7$ do Ministério da Agricultura, Pecuária e Abastecimento de 15 de agosto de 
Tabela 1. Umidade do grão, Peso do Hectolitro (PH), Peso de Mil Grãos (PMG), extração de farinha, farinha de quebra, Número de Queda (NQ), umidade, cinzas e proteína bruta da farinha de trigo de amostras de grãos dos genótipos BRS 179, Rubi, Fundacep 30 e Fundacep 51.

\begin{tabular}{lcrcc}
\hline \multicolumn{1}{c}{ Determinação } & BRS 179 & \multicolumn{1}{c}{ Rubi } & Fundacep 30 & Fundacep 51 \\
\hline Umidade do grão (\%) & $10,51^{\mathrm{b}}$ & $9,95^{\mathrm{b}}$ & $10,40^{\mathrm{b}}$ & $11,18^{\mathrm{a}}$ \\
PH (kg.hL ${ }^{-1}$ ) & $74,3^{\mathrm{d}}$ & $78,65^{\mathrm{b}}$ & $76,18^{\mathrm{c}}$ & $80,13^{\mathrm{a}}$ \\
PMG (g) & $31,12^{\mathrm{c}}$ & $26,87^{\mathrm{d}}$ & $33,62^{\mathrm{b}}$ & $38,46^{\mathrm{a}}$ \\
Extração de farinha (\%) & $61,85^{\mathrm{b}}$ & $62,05^{\mathrm{b}}$ & $66,23^{\mathrm{a}}$ & $65,74^{\mathrm{a}}$ \\
Farinha de quebra (\%) & $29,44^{\mathrm{a}}$ & $15,74^{\mathrm{d}}$ & $22,22^{\mathrm{b}}$ & $19,31^{\mathrm{c}}$ \\
NQ (s) & $348^{\mathrm{b}}$ & $465^{\mathrm{a}}$ & $363^{\mathrm{b}}$ & $356^{\mathrm{b}}$ \\
Umidade da farinha (\%) & $15,08^{\mathrm{b}}$ & $16,40^{\mathrm{a}}$ & $14,90^{\mathrm{c}}$ & $14,84^{\mathrm{c}}$ \\
Cinzas (\%) & $0,51^{\mathrm{b}}$ & $0,48^{\mathrm{b}}$ & $0,75^{\mathrm{a}}$ & $0,55^{\mathrm{b}}$ \\
Proteína bruta (\%) & $11,42^{\mathrm{c}}$ & $12,57^{\mathrm{a}}$ & $12,67^{\mathrm{a}}$ & $12,08^{\mathrm{b}}$ \\
\hline
\end{tabular}

${ }^{1}$ Médias seguidas das mesmas letras na linha não diferem estatisticamente pelo teste de Tukey a $5 \%$ de probabilidade de erro.

2001 para a classificação do trigo em tipo ${ }^{4}$. O maior valor de umidade foi encontrado no cultivar Fundacep 51, seguido de BRS 179, Fundacep 30 e Rubi.

O peso do hectolitro nas amostras variou entre 74,3 e 80,13 kg.hL ${ }^{-1}$, sendo o cultivar Fundacep 51 significativamente superior aos demais cultivares, seguido de Rubi, ambos classificados como tipo 1. Os cultivares Fundacep 30 e BRS 179 apresentaram menores valores de $\mathrm{PH}$, estando classificados em tipo 2 e tipo 3, respectivamente (2001).

O peso de mil grãos (PMG) variou significativamente entre as amostras analisadas, com valor de 32,51 g, em média (Tabela 1). O cultivar Fundacep 51 apresentou maior valor, sendo classificado como grão médio (1996). As amostras dos cultivares BRS 179, Rubi e Fundacep 30 apresentaram menores valores de PMG, estando classificados como grãos pequenos. O PMG é utilizado para classificar o trigo pelo tamanho. Os grãos de tamanho excessivo não são desejados pela indústria, pois podem provocar perdas devido às dificuldades de regulagem dos equipamentos de limpeza e moagem, enquanto grãos pequenos podem passar pelas peneiras de limpeza e causar perdas na produção de farinha pela diminuição da quantidade de trigo moído (GUARIENTI, 1996). A diferença de tamanho também influencia na quantidade de água absorvida, pois os grãos pequenos absorvem maior quantidade de água em relação aos grãos grandes durante a etapa de condicionamento do trigo (POSNER; HIBBS, 1999).

O grau de extração da farinha variou entre 61,85 e 66,23\%, sendo significativamente superior nos cultivares Fundacep 30 e Fundacep 51 (Tabela 1). O valor de rendimento de farinha de quebra variou entre 15,74 e $29,44 \%$, sendo significativamente inferior para o cultivar Rubi, devido à maior dureza do grão. De acordo com Guarienti (1996), os trigos duros apresentam menores taxas de extração e de farinha de quebra, enquanto em trigos moles e semimoles são verificados maiores valores de extração de farinha de quebra.

O número de queda das amostras de farinha de trigo apresentou valores médios entre 348 e 465 segundos (Tabela 1), sendo significativamente superior o cultivar Rubi. Os trigos analisados apresentaram número de queda acima do preconizado pela legislação brasileira (BRASIL, 2001), para fins de definição da classe, que é de 200 segundos. O número de queda é usado para avaliar a atividade da enzima $\alpha$-amilase de grãos e farinhas, a fim de detectar danos causados pela germinação na espiga. $\mathrm{O}$ excesso de $\alpha$-amilase causa problemas na produção de pão como descoloração da crosta, miolo seco e pequeno volume (PERTEN INSTRUMENTS, 2007).

Dimmock e Gooding (2002) verificaram que o número de queda está negativamente associado com o teor de umidade e peso médio do grão. Carneiro et al. (2005), estudando a influência do período de armazenamento de grãos na qualidade de farinha de trigo, verificaram redução significativa da atividade das enzimas amilolíticas com o retardamento da colheita e com o aumento do tempo de maturação do grão.

A umidade da farinha analisada pelo NIR não variou significativamente entre os genótipos Fundacep 30 e Fundacep 51, sendo significativamente inferior às amostras de BRS 197 e Rubi (Tabela 1). No genótipo Rubi, a elevada umidade se deve ao condicionamento realizado com maior umidade, por tratar-se de grão duro. A operação de condicionamento de grãos visa obter uma separação eficiente do farelo e endosperma, com mínimo teor de cinzas na farinha, sendo influenciado pelo teor de umidade, temperatura e tempo de tratamento. A umidade é o fator mais importante e a quantidade de água varia com a dureza do grão (POSNER; HIBBS, 1999).O teor de cinzas variou entre 0,48 e 0,75\% estimado em base seca, sendo encontrado maior valor no genótipo Fundacep 30, sem variar significativamente entre os demais cultivares estudados (Tabela 1). A proteína bruta variou de 11,42 a 12,67\%, valores expressos em base seca. $\mathrm{O}$ menor valor de proteínas foi verificado no genótipo BRS 179, o que permite classificá-lo como de baixa qualidade (GUARIENTI, 1996). Os genótipos Rubi e Fundacep 30 foram significativamente superiores quanto ao teor de proteínas, podendo ser classificados como de média qualidade. O conteúdo de proteínas do grão de trigo é afetado pelo local de plantio, pelas condições climáticas (chuva e temperatura durante a fase de maturação do grão), pelas práticas culturais (rotação de cultura, adubação nitrogenada), pelas doenças, pelas pragas e, também, pelo genótipo (GUARIENTI, 1996). Para a elaboração de produtos de panificação, deve-se avaliar a quantidade e a qualidade de proteínas presentes na farinha de trigo. A qualidade das proteínas está relacionada à capacidade de formação da massa, ou seja, quando farinha de trigo e água são misturadas, o resultado é a formação de uma massa constituída pela rede protéica do glúten ligada aos grânulos de amido que retêm o gás formado, e isso produz o aumento de volume (BUSHUK, 1985).

\subsection{Propriedades físicas e reológicas da farinha de trigo}

O número de queda dos genótipos BRS 179, Rubi, Fundacep 30 e Fundacep 51 aumentou com o tempo de maturação do trigo (Figura 1). Os modelos de regressão foram significativos nos quatro genótipos estudados, sendo utilizados no ajuste somente termos lineares. O melhor ajuste foi verificado no genótipo Rubi, com coeficiente de determinação de 0,91 , seguido de Fundacep 51 e BRS 179. Nos grãos do genótipo Rubi, o número de queda foi significativamente maior.

O número de queda permite estimar a capacidade de fermentação da massa de determinada farinha, pois, quanto maior o valor encontrado, menor a atividade amilásica, o que dificulta o 
processo industrial. A quantidade de enzima presente nas farinhas tem uma influência direta sobre a qualidade do pão produzido. Em atividade enzimática de 200 a 350 segundos, o pão apresenta miolo firme com grande volume e textura macia. De outro modo, os pães elaborados com farinha de atividade enzimática alta (NQ menor que 200 segundos) ou baixa (maior que 350 segundos) apresentam volume reduzido e características internas e externas indesejáveis. $\mathrm{O}$ valor do número de queda apresenta relação inversa com a atividade da alfa-amilase, ou seja, quanto maior o valor da atividade da alfa-amilase menor o valor do número de queda (PERTEN INSTRUMENTS, 2007). Neste estudo, os valores de número de queda que já se encontravam elevados na colheita do trigo, apresentaram aumento com o período de maturação, o que exige a adição de maiores quantidades de enzimas amilolíticas para a utilização da farinha em produtos de panificação. Porém, a baixa atividade não é um problema de difícil solução, pois, normalmente, a formulação dos reforçadores ou melhoradores utilizados em panificação apresenta enzima alfa-amilase fúngica, com a finalidade de correção dessa deficiência na farinha de trigo (GUARIENTI, 1996). Os resultados estão em acordo com Carneiro et al. (2005), que verificaram elevação dos valores de número de queda com o aumento do período de armazenagem de grãos de trigo comum e durum.

Nas Figuras 2 e 3, estão representadas as variações da luminosidade $\left(\mathrm{L}^{*}\right)$ e intensidade de amarelo $\left(+\mathrm{b}^{*}\right)$, de cor em função do tempo de maturação de grãos de trigo. A cor da farinha é avaliada pelas medidas de luminosidade e intensidade de amarelo. A luminosidade da farinha é afetada pelo conteúdo de farelo ou material estranho, enquanto a intensidade de amarelo está relacionada com a quantidade de pigmentos presentes no trigo.

A cor de um produto é definida pelo uso da escala de cor tridimensional que descreve os diferentes componentes da cor. A luz refletida é composta de um componente escuro ou luminoso em adição a um vermelho ou verde e um componente azul ou amarelo, determinada por colorímetros ou espectrofotômetros (COULTATE, 2004). A cor da farinha de trigo deixou de ser uma avaliação visual, passando a fazer parte do controle de qualidade. A intensidade do componente $\mathrm{L}^{*}$ de cor (lumi-

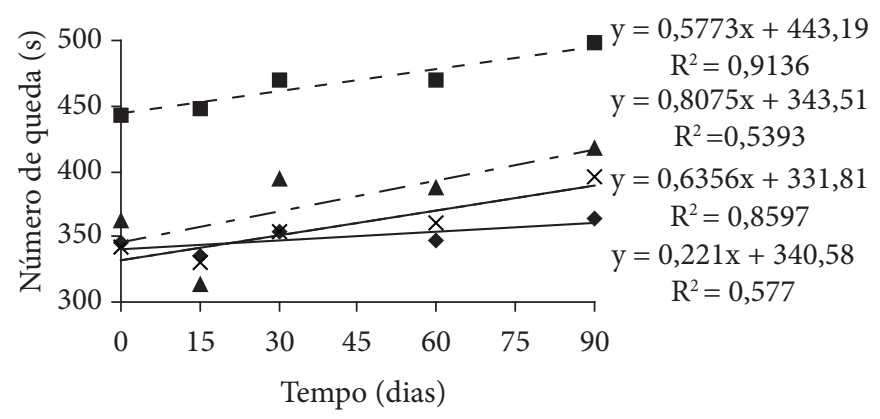

$$
\begin{array}{|ll|}
\hline \text { • BRS 179 } & \boldsymbol{\square} \text { Rubi } \\
\text { \ Fundacep 30 } & \times \text { Fundacep 51 } \\
\hline
\end{array}
$$

Figura 1. Número de queda de amostras de farinha de trigo dos genótipos BRS 179, Rubi, Fundacep 30 e Fundacep 51, durante 90 dias de maturação do grão. nosidade) aumentou com o tempo de maturação do trigo em todos os genótipos estudados, sendo verificado o maior valor no BRS 179. No genótipo Rubi, apesar de ter ocorrido aumento de $L^{*}$, o modelo de regressão não foi significativo $\left(R^{2}=0,29\right)$. De forma concomitante ocorreu redução do componente de cor $+b^{*}$ (amarelo), sendo significativos todos os modelos de regressão estudados, com coeficientes de determinação variando entre 0,61 e 0,80 (Figura 3). A maior alteração do componente $L^{*}$ de cor verificada no genótipo BRS 179, provavelmente está relacionado com a menor dureza do grão, pois foi o que apresentou o maior rendimento de farinha de quebra (Tabela 1).

A alveografia é um teste reológico usado em vários países para a determinação de características qualitativas da farinha através dos parâmetros força geral do glúten $\left(\mathrm{W} \times 10^{-4} \mathrm{~J}\right)$, relação elasticidade e extensibilidade $(\mathrm{P} / \mathrm{L})$ e Índice de Elasticidade (IE). A expressão força de glúten normalmente é utilizada para designar a maior ou menor capacidade de uma farinha sofrer um tratamento mecânico ao ser misturada com água. Também é associada à maior ou menor capacidade de absorção de água pelas proteínas formadoras de glúten, que combinadas

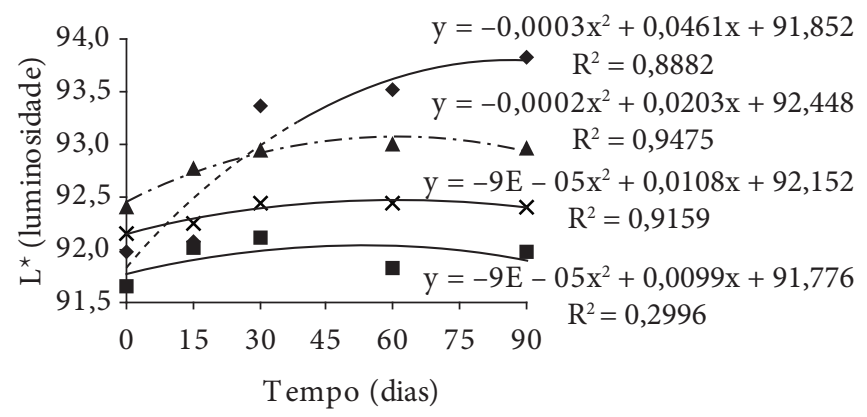

\begin{tabular}{|ll|}
\hline • BRS 179 & Rubi \\
\ Fundacep 30 & $\times$ Fundacep 51 \\
\hline
\end{tabular}

Figura 2. Componente $\mathrm{L}^{\star}$ de cor (luminosidade) da farinha de trigo dos genótipos BRS 179, Rubi, Fundacep 30 e Fundacep 51, durante 90 dias de maturação do grão.

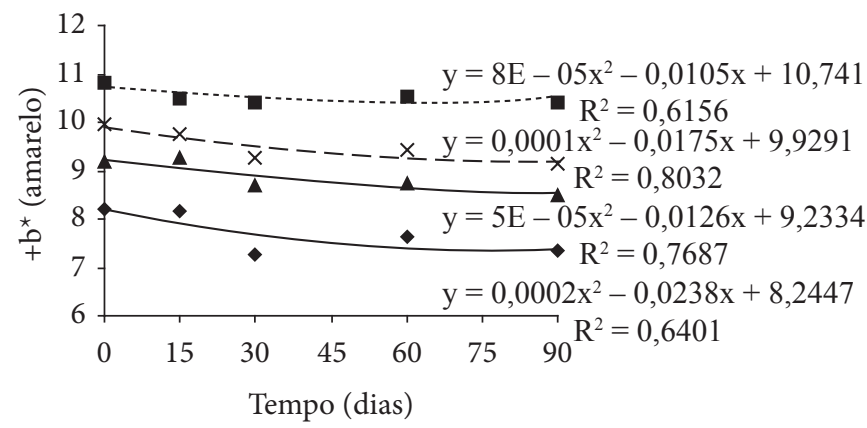

\begin{tabular}{|ll|}
\hline • BRS 179 & $\boldsymbol{\square}$ Rubi \\
\ Fundacep 30 & $\times$ Fundacep 51 \\
\hline
\end{tabular}

Figura 3. Componente $+\mathrm{b}^{\star}$ de cor (amarelo) da farinha de trigo dos genótipos BRS 179, Rubi, Fundacep 30 e Fundacep 51, durante 90 dias de maturação do grão. 
à capacidade de retenção do gás carbônico resultam em um pão de volume aceitável, textura interna sedosa e de granulometria aberta (DOBRASZCZYK; MORGENSTERN, 2003).

$\mathrm{O} \mathrm{W}$, obtido através da medida da área da curva do alveograma, aumentou em todos os genótipos de trigo estudados o tempo de maturação do grão (Figura 4). Na colheita, os genótipos de trigo BRS 179, Fundacep 51 e Rubi foram classificados como brando, brando e pão (BRASIL, 2001), passando para pão, pão e melhorador após o período de 90 dias de maturação do grão de trigo. Isto mostra a importância de realizar a maturação do trigo antes da moagem visando a melhoria da qualidade para a utilização final.

O balanço preciso das propriedades viscoelásticas da massa é fator essencial para a determinação de uso final. A presença de glúten elástico é necessária tanto em farinhas de panificação, quanto de massas alimentícias, enquanto que um glúten menos elástico é requerido em farinhas para bolos e biscoitos (DOBRASZCZYK; MORGENSTERN, 2003). Os resultados deste trabalho estão em acordo com os de Carneiro et al. (2005), que observaram aumento do valor de $\mathrm{W}$ em todos os tratamentos estudados com o aumento do tempo de armazenagem de trigo.

A farinografia é um dos mais completos e sensíveis testes para a avaliação da qualidade de mistura da massa de farinha de trigo. Alguns parâmetros determinados pela farinografia são absorção de água, tempo de chegada, tempo de desenvolvimento, tempo de saída e estabilidade (GUARIENTI, 1996). As avaliações de farinografia (Figura 5), com base no tempo de estabilidade mostram que somente os genótipos Rubi e Fundacep 51 apresentaram modelos de regressão significativos. A equação de melhor ajuste foi obtida no genótipo Rubi, com coeficiente de determinação de 0,82 . Neste genótipo, também foram verificados os maiores valores para estabilidade, seguido de Fundacep 30. A estabilidade, determinada em farinógrafo, normalmente se correlaciona com a força geral do glúten $(\mathrm{W})$, sendo um indicador de qualidade preferido para análise de trigos de grãos duros, como no Rubi. Para trigos moles e semiduros a alveografia tem se mostrado mais adequada para predizer a qualidade de uso final do trigo em estudo (GUTKOSKI, 2007).

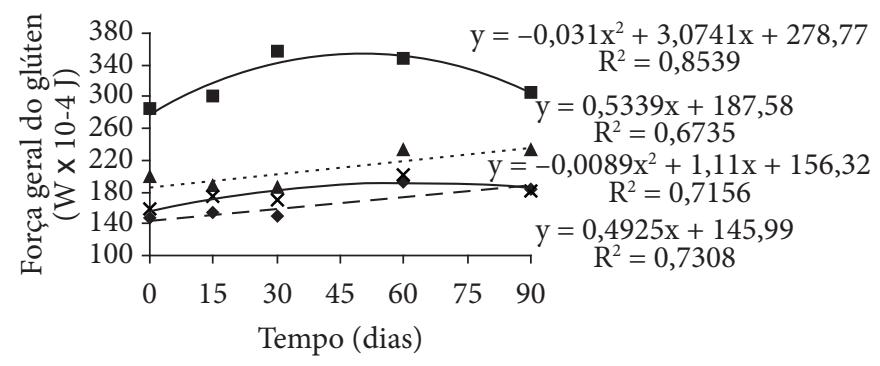

\begin{tabular}{|ll|}
\hline • BRS 179 & — Rubi \\
\ Fundacep 30 & $\times$ Fundacep 51 \\
\hline
\end{tabular}

Figura 4. Força geral do glúten $\left(\mathrm{W} \times 10^{-4} \mathrm{~J}\right)$ da farinha de trigo dos genótipos BRS 179, Rubi, Fundacep 30 e Fundacep 51, durante 90 dias de maturação do grão.
Durante a moagem do grão de trigo, à medida que o endosperma é reduzido em partículas menores, alguns grânulos de amido são danificados mecanicamente e isto tem um efeito pronunciado nas características de absorção de água na farinha. A proteína bruta absorve de $250 \%$ a $300 \%$ do seu peso em água, o amido normal, $33 \%$ e o amido danificado, $100 \%$. Desta forma, a absorção de água pela farinha de trigo pode variar em função da porcentagem de amido danificado produzido durante a moagem (MORRISON, 1994). Devido à ação dos rolos de quebra e, principalmente, dos de redução, parte dos grânulos de amido são fisicamente danificados.

Com o aumento do período de maturação do grão, as farinhas dos genótipos BRS 179 e Fundacep 51 apresentaram redução no teor de amido danificado (Figura 6). Nos genótipos Rubi e Fundacep 30, os modelos de regressão não foram significativos. A porcentagem de amido danificado se correlaciona com análises de controle de qualidade da farinha de trigo (MORGAN; WILLIAMS, 1995), por alterar a absorção de água, a produção de açúcar e a qualidade dos produtos de panificação. Baixo teor de

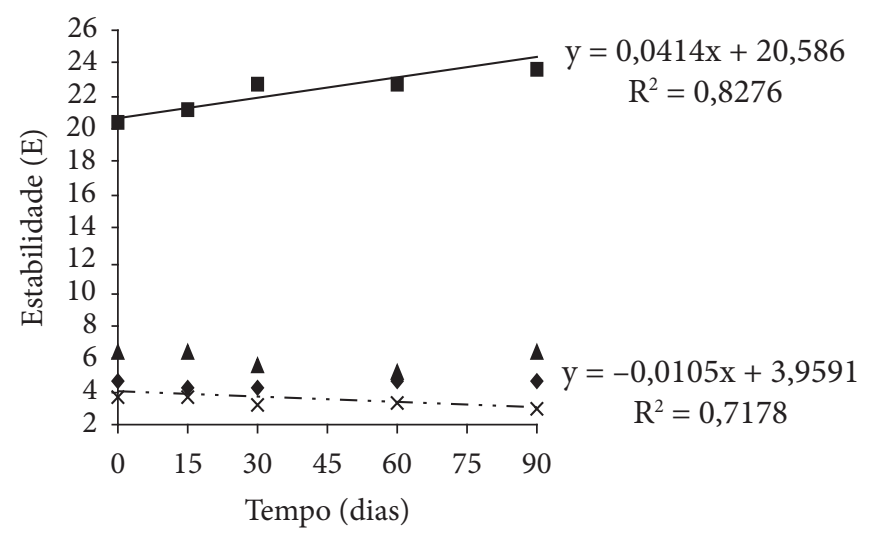

\begin{tabular}{|ll|}
\hline • BRS 179 & Rubi \\
\ Fundacep 30 & $\times$ Fundacep 51 \\
\hline
\end{tabular}

Figura 5. Estabilidade da farinha (E) da farinha de trigo dos genótipos BRS 179, Rubi, Fundacep 30 e Fundacep 51, durante 90 dias de maturação do grão.

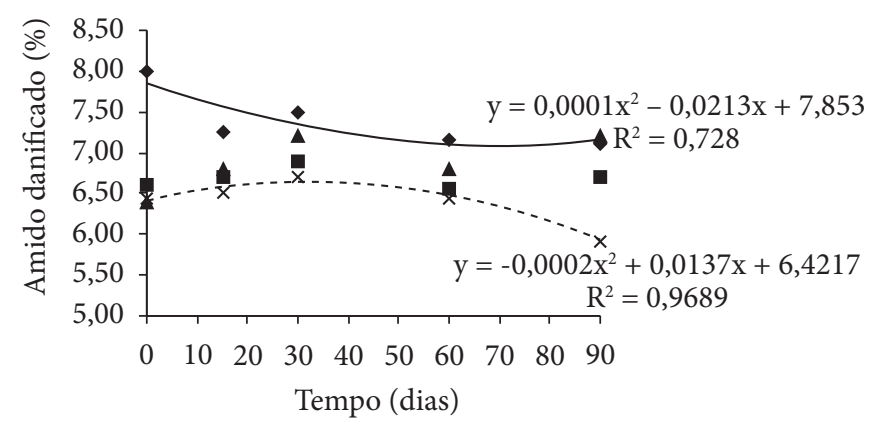

Figura 6. Amido danificado da farinha de trigo dos genótipos BRS 179, Rubi, Fundacep 30 e Fundacep 51, durante 90 dias de maturação do grão. 
amido danificado é desejável na produção de biscoitos. De acordo com Gutkoski et al. (2007) o teor de amido danificado produzido durante a moagem de trigo influencia nas propriedades funcionais de biscoitos, apresentando melhor resultado aqueles obtidos a partir de uma passagem pelo conjunto de quebra. Na panificação, $o$ recomendado é que o teor de amido danificado esteja entre 6 e $9 \%$ (LABUSCHAGNE; CLAASSEN; DEVENTER, 1997).

\section{Conclusões}

Com o aumento do período de maturação dos grãos de trigo, a farinha apresentou melhores propriedades físicas e reológicas avaliadas pelas alterações de número de queda, cor, alveografia e farinografia.

Os resultados de atividade enzimática, intensidade de $\mathrm{L}^{*}$ (luminosidade), intensidade de $+\mathrm{b}^{\star}$ (amarelo) e força geral do glúten $\left(\mathrm{W} \times 10^{-4} \mathrm{~J}\right)$ se mostraram efetivos na avaliação de propriedades físicas e reológicas durante o período de maturação do trigo. Por outro lado, as avaliações de amido danificado e estabilidade não foram indicadores adequados. Para estudar o período de maturação do trigo, é indicado incluir a avaliação funcional da farinha.

O trigo não deve ser comercializado logo após a colheita, pois apresenta melhoria na classificação comercial, sendo indicado com base nos resultados deste trabalho um período de maturação de no mínimo 60 dias. Neste estudo, os genótipos de trigo BRS 179 e Fundacep 51 passaram das classes brando para pão, enquanto o Rubi de pão para melhorador, indicando maior valor tecnológico e comercial com o aumento do período de maturação dos grãos de trigo.

\section{Agradecimentos}

Aos programas Pibic/UPF e Bic/Fapergs pelas bolsas de iniciação científica. Ao CNPq pela bolsa produtividade em pesquisa. Ao Eng.-Agr. Mauro André Binfeld da Cotricampo, Campo Novo, RS, pelo fornecimento de material experimental.

\section{Referências bibliográficas}

AACC - AMERICAN ASSOCIATION OF CEREAL CHEMISTS. Approved methods of the American Association of Cereal Chemists. 9 ed. Saint Paul: AACC, 1995. v. 2.

BACALTCHUK, B. Qualidade dos alimentos exigida pelos consumidores no século XXI. In: CONFERÊNCIA BRASILEIRA DE PÓSCOLHEITA, 1, 1999, Porto Alegre. Anais... Passo Fundo: Embrapa Trigo, p. 13-22, 1999.

BRASIL. MINISTÉRIO DA AGRICULTURA, DO ABASTECIMENTO E DA REFORMA AGRÁRIA. Secretaria Nacional de Defesa Agropecuária. Regras para análise de sementes. Brasília:DNDV/CLAV, $1992.365 \mathrm{p}$.

BRASIL. MINISTÉRIO DA AGRICULTURA, PECUÁRIA E ABASTECIMENTO. Instrução Normativa SARC no ${ }^{\circ}$, de 15 de agosto de 2001. Aprova o regulamento técnico de identidade e qualidade do trigo. Diário Oficial da República Federativa do Brasil, Brasília, 21 de agosto de 2001.

BUSHUK, W. Flour proteins: structure and functionality in dough and bread. Cereal Foods World, v. 30, n. 7, p. 447-451, 1985.

CALDEIRA, M. et al. Diversidade de trigos, tipificação de farinhas e genotipagem. Biotecnologia e Desenvolvimento, v. 1, n. 1, p. 44-48, 2003.
CARNEIRO, L. M. T. A. et al. Diferentes épocas de colheita, secagem e armazenamento na qualidade de grãos de trigo comum e duro. Bragantia, v. 64, n. 1, p. 127-137, 2005.

CENKOWSKI, S.; DEXTER, J. E.; SCANLON, M. G. Mechanical compaction of flour: the effect of storage temperature on dough rheological properties. Canadian Agricultural Engineering, v. 42, n. 1, p. 5.1-5.17, 2000.

CHEN, X.; SCHOFIELD, J. D. Changes in the glutathione and breadmaking performance of white wheat flour during short-term storage. Cereal Chemistry, v. 73, n. 1, p. 1-4, 1996.

COULTATE, T. P. Alimentos: a química de seus componentes. 3 ed. Porto Alegre: Artmed, 2004. 368 p.

DIMMOCK, J. P. R. E.; GOODING, M. J. The effects of fungicides on Hagberg falling number and blackpoint in winter wheat. Crop Protection, v. 21, n. 3, p. 475-487, 2002.

DOBRASZCZYK, B. J.; MORGENSTERN, M. P. Rheology and the breadmaking process. Journal of Cereal Science, v. 38, n. 2, p. 229-245, 2003.

ELIAS, M. C. Fatores que influenciam a aeração e o manejo da conservação de grãos. In: Lorini, I. et al. (Ed.). Armazenagem de grãos. Campinas: IBG, 2002. Cap. 6.1, p. 311-359.

FLEURAT-LESSARD, F. Qualitative reasoning and integrated management of the quality of stored grain: a promising new approach. Journal of Stored Products Research, v. 38, n. 2, p. 191-218, 2002.

GUARIENTI, E. M. Qualidade industrial de trigo. 2 ed. Passo Fundo: Embrapa Trigo, 1996.

GUTKOSKI, L. C. et al. Características tecnológicas de genótipos de trigo cultivados no cerrado. Ciência e Agrotecnolologia, v. 31, n. 3, p. 786-792, 2007a.

GUTKOSKI, L. C. et al. Efeito do teor de amido danificado na produção de biscoitos tipo semi-duros. Ciência e Tecnologia de Alimentos, v. 27, n. 1, p. 119-124, 2007b.

HRUSKOVÁ, M.; MACHOVÁ. D. Changes of wheat flour properties during short term storage. Czech Journal of Food Sciences, v. 20, n. 4, p. 125-130, 2003

KOCH, H. J.; PRINGAS, C.; MAERLAENDER, B. Evaluation of environmental and management effects on Fusarium head blight infection and deoxynivalenol concentration in the grain of winter wheat. European Journal of Agronomy, v. 24, n. 2, p. 357-366, 2006.

LABUSCHAGNE, M. T.; CLAASSEN, A.; DEVENTER, C. S. Biscuitmaking quality of backcross derivatives of wheat differing in kernel hardness. Euphytica, v. 96, n. 1, p. 263-266, 1997

MORGAN, J. E.; WILLIAMS, P. C. Starch damage in wheat flours: a comparison of enzymatic, iodometric, and near-infrared reflectance techniques. Cereal Chemistry, v. 72, n. 2, p. 200-212, 1995.

MORRISON, W. R. et al. Properties of damage starch granules. III. Microscopy and particle size analysis of undamaged granules and remnants. Journal of Cereal Science, v. 20, n. 2, p. 59-67, 1994.

PERTEN INSTRUMENTS. Falling number. Disponível em: http:// www.perten.com/pages/ProductPage__ 367.aspx?epslanguage=EN . Acesso em: 8 mar. 2007.

POSNER, E. S.; HIBBS, A. N. Wheat flour milling. 2 ed. Minnesota: American Association of Cereal Chemists, 1999. 341 p.

POMERANZ, Y. Modern cereal science and technology. New York: VHC Publishers, 1987. 486p.

PROMYLOGRAPH. Betriebsanleitung für den promylograph. Blasen: Max Egger, 2001.

SAS-SATATISTICAL ANALYSIS SYSTEM. User's guide: statistics. 5 ed. Cary, 1985. 956p. 